\title{
LOCAL ELECTRON DENSITY MODELS FOR TI TO Pb CONVERSION IN LORANDITE
}

\author{
I. GRŽETIĆ
}

Faculty of Mining and Geologv, Unversity in Belgrade, Unversity Laboratory for Electron Microanalysts, 11000 Belgrade, Yugosiavia

The nuclear conversion of ${ }^{205} \mathrm{Tl}$ to ${ }^{205} \mathrm{~Pb}$ by neutrino capture, lorandite $\left(\mathrm{TlAsS}_{2}\right.$ ) converts into Pb-bearing lorandite $\left(\mathrm{Tl}_{1-x} \mathrm{~Pb}_{x} \mathrm{AsS}_{2}\right)$ where $x$ is a very small number.

Having used a highly simplified cluster model of lorandite, we intended to calculate the electron density of $\mathrm{Tl}$ and 1 ts neighbouring atoms by the quantum chemical discrete variational method $[5,6]$.

Substituting $\mathrm{Pb}$ for $\mathrm{Tl}$ in the lattice site of $\mathrm{Tl}$ and calculatıng the difference existing between these two clusters, we would like to discuss the possible changes of the cluster's stability and the relative binding between $\mathrm{Tl}-\mathrm{S}$ and $\mathrm{Pb}-\mathrm{S}$ in lorandite.

\section{Introduction}

Solar neutrino detection is faced nowadays with several unsolved questions when the processes occurring on the Sun are in question and problems connected with the way in which the neutrino is or will be detected on the Earth.

The 1sotope of ${ }^{205} \mathrm{Tl}$ has proved to be a convenient solar neutrino detector due to its low neutrino capture energetic threshold $(45 \mathrm{keV})$, although the time needed for the performance of a sufficient number of captures, according to the following reaction,

${ }^{205} \mathrm{Tl}+\nu \rightarrow{ }^{205} \mathrm{~Pb}+\mathrm{e}^{-}$,

requires utilization of a detector that contains as high a $\mathrm{Tl}$ concentration as in lorandite from Allchar (Yugoslavia) [1].

The lorandite that contains in its lattice traces of $\mathrm{Pb}$ at sites of $\mathrm{Tl}$ results from conversion of ${ }^{205} \mathrm{Tl}$ to ${ }^{205} \mathrm{~Pb}$. Such lorandite (TlAsS ${ }_{2}$ ) will have a new $\mathrm{Tl}_{1-x} \mathrm{~Pb}_{x} \mathrm{AsS}_{2}$ formula. We were interested in the very stability of a lorandite crystal lattice and its possible destruction or increment in the lattice energy followed by the appearrance of $\mathrm{Pb}$ atoms in a lattice, as well as in effects that might result from the change of a lorandite lattice caused by diffusion of $\mathrm{Pb}$ atoms out from the inner part of a crystal towards its surface.

The aim of this paper from a purely crystallochemical point of view is the investigation of the influence of trace elements on lattice properties, particularly the changes caused by inserting $\mathrm{Pb}$ atoms in the lattice of the host mineral - lorandite. Investigation of this process was possible due to application of the appropriate quantum chemical theoretical approach to an adequate mineral model.

\section{Experiment}

The three quantum chemical programs SCF- $\mathrm{X}_{\alpha}$ [2], LMTO [3] and DVM [4-6] * were at our disposal. The decision which of the mentioned programs would give us optimal results regarding the geometry of the lorandite lattice and possible models were made balancing the efficiency to reproduce the geometry of the mentioned mineral and the length of the computing time.

As is known, lorandite belongs to a $\mathrm{P} 2 /$ a space group that must be simplified when utilization of any of the mentioned programs is concerned and, further, calculations are possible for clusters only, not for an infinite lattice. Comparison of the mentioned programs proved that LMTO requires a long computing time and enormous matrix space to compute the offered cluster. In our decision which of the two remaining programs to choose, the crucial fact was that the DVM method offers better results in the case of open structures where the covalent character of the chemical bond predominates as in sulphosalts like lorandite. This kind of problem can be handled by non relativistic calculations with frozen inner electrons and no cluster relaxation and application of a Wotson sphere in order to perform both neutralization and stability of a negatively charge clusters.

This program provides us with the following results: - coefficients of LCAO for the corresponding molecular orbitals,

- proper electron function values,

\footnotetext{
* SCF $-\mathrm{X}_{\alpha}=$ self-consistent field $-\mathrm{X}_{\alpha}$ clustered wave cluster molecular orbital method.

LMTO = linear muffin tin orbitals.

DVM = discrete variational method.
} 
- distribution of electron densities within the interatomic space encompassing the atoms, valent regions in a cluster,

- a graph of electron densities in a given plane, and

- electron level densities.

Among the presented results we were particularly interested in those regarding electron densities.

\section{A simplified lorandite structure}

The lorandite structure was determined in 1973 by Fleet [7] and therefore we shall not discuss here the already known structure, but shall focus our attention on the simplification of the mentioned mineral to a model that was acceptable for calculation by DVM.

The symmetry most similar to the original lorandite $\mathrm{P} 2_{1 / a}$ symmetry is $\mathrm{C}_{2 \mathrm{v}}$. Within the framework of this symmetry a cluster $\mathrm{TlS}_{7}^{-13}$ with $\mathrm{Tl}^{+}$as a central atom $(0,0,0)$ and $7 \mathrm{~S}^{-2}$ distributed around the central atom was noticed. Sulphur atoms were arranged in such a way that one atom is located on the $Z$ axis at a distance of $0.322 \mathrm{~nm}(0,0,0.322)$ and four other sulphur atoms are located in a square arrangement in the $x-y$ plane $(-0.228,-0.228,0),(0.228 .-0.228,0)(-0.228,0.228$, $0)$ and $(0.228,0.228,0)$. The last two sulphur atoms are placed in the $y-z$ plane $(0,0.228,-0.296)$ and 0 , $-0.228,-0.296$ ) at a distance of $0.374 \mathrm{~nm}$ from the central atom. As is evident from fig. $1 \mathrm{Tl}$ and $5 \mathrm{~S}$ (at a distance of $0.322 \mathrm{~nm}$ ) lie within a layer having cubic symmetry and the remaining two $S$ atoms at a distance of $0.374 \mathrm{~nm}$ lie in a neighbouring layer of the same symmetry, but which is shifted in such a way that a projection of $\mathrm{Tl}$ ions from one layer falls into the center of a square side of another layer. During conversion of ${ }^{205} \mathrm{Tl}$ to ${ }^{205} \mathrm{~Pb}$, the $\mathrm{Pb}$ atom occupies the site of $\mathrm{Tl}$ in the cluster so that the new $\mathrm{PbS}_{7}^{-13}$ cluster is identical to the old one, and the difference between these two clusters is only in the electron configuration of $\mathrm{Tl}$ and $\mathrm{Pb}$.

\section{Obtained results}

The total amount of valence electrons in a $\mathrm{TlS}_{7}^{-13}$ cluster is 58 and 59 in $\mathrm{PbS}_{7}^{-13}$. The difference between these two clusters can be most clearly seen from the results of electron density analysis which refer to valence electrons as the inner electrons are frozen. This means that all the changes are studied on the basis of a different distribution of the total amount of electrons (58 and 59) in two different clusters having the same lattice geometry. This redistribution is determined in the following way. A space net of spots is generated within the clusters and the electron density [4] is determined by a discrete variation method for each spot.

The electron densities characterizing $\mathrm{TlS}_{7}^{-13}$ and $\mathrm{PbS}_{7}^{-13}$ clusters in the $x-y$ plane, encompassing a metal and 4 sulphur atoms at a distance of $0.322 \mathrm{~nm}$, are presented in figs. 2 and 3 . The analysis of electron densities indicates the following:

- the relative electron density within a cluster is higher along the $y$ axis than along the $x$ axis, as the presence of the two $\mathrm{S}$ atoms (fig. 1) which lie in the $y-x$ plane influence the electron density between a metal ( $\mathrm{Tl}$ or $\mathrm{Pb}$ ) and $\mathrm{S}$ ligands in the $x-y$ plane,

- the electron density of the $\mathrm{TlS}_{7}^{-13}$ cluster is redistributed in a different way when compared to the $\mathrm{PbS}_{7}^{-13}$ cluster.
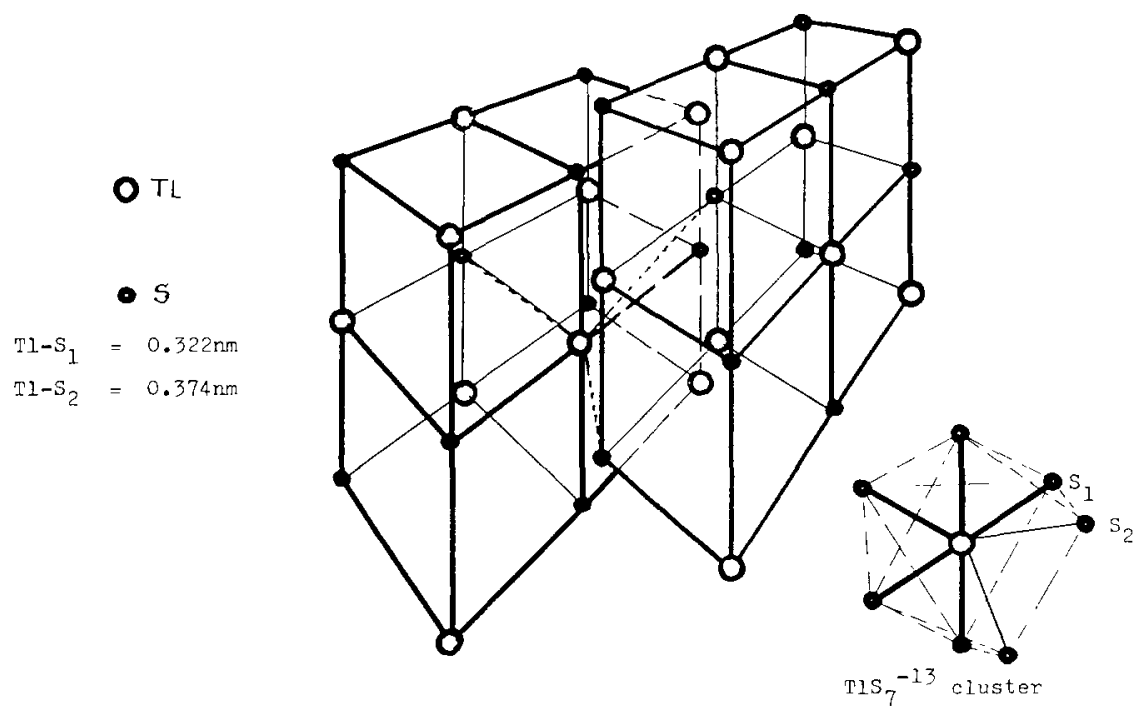

Fig. 1. A simplified structure of lorandite $\left(\mathrm{TlAsS}_{2}\right)$. 


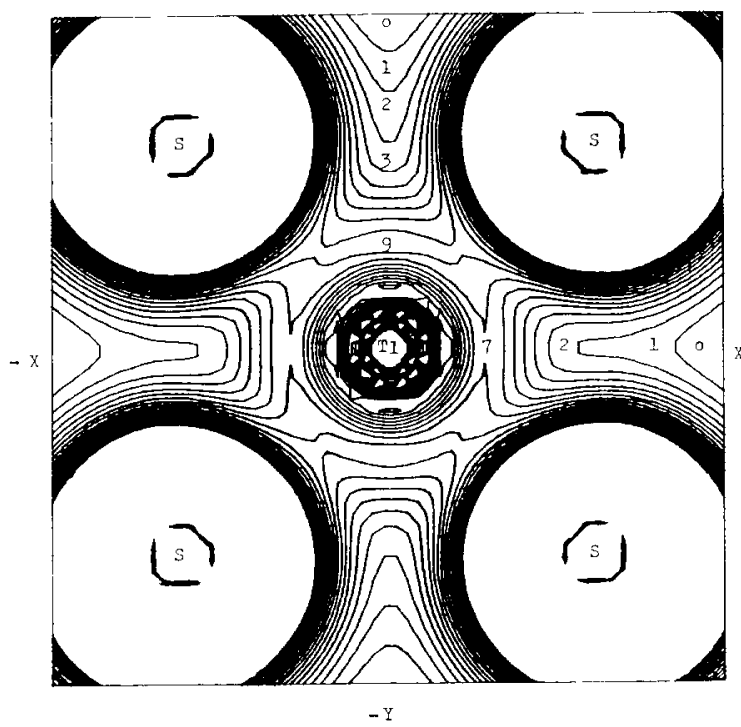

Fig. 2. $\mathrm{TIS}_{\gamma}^{-13}$ cluster, electron density plot in the $x-y$ plane

In fig. 4 the difference in electron density between these two clusters is represented. Part of a field with a negative value indicates a far higher electron density near $\mathrm{Pb}$ than in the vicinity of $\mathrm{Tl}$, but on the other hand a positive value penetrating deep into a cluster along the $y$ axis is also evident. This suggests that in $\mathrm{TIS}_{7}^{-13}$ the charge density is probably higher in the $y-z$ plane than in $\mathrm{PbS}_{7}^{-13}$.

In order to confirm the above mentioned statement we investigated electron densities withın this plane. Figs. 5 and 6 show electron densites within $\mathrm{TlS}_{7}$ and $\mathrm{PbS}_{7}$ clusters. In this connection it should be mentioned

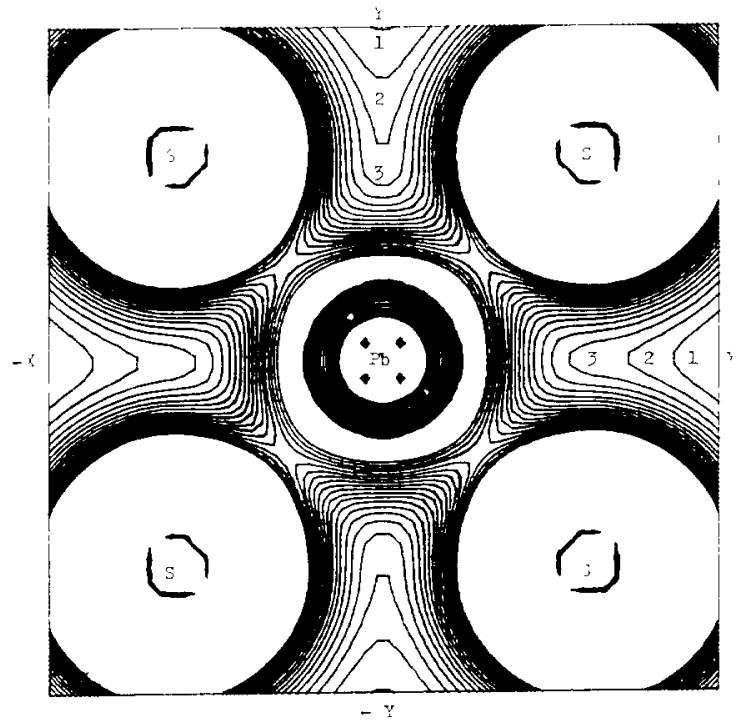

Fig. 3. $\mathrm{PbS}_{7}^{-13}$ cluster; electron density plot in the $x-y$ plane.

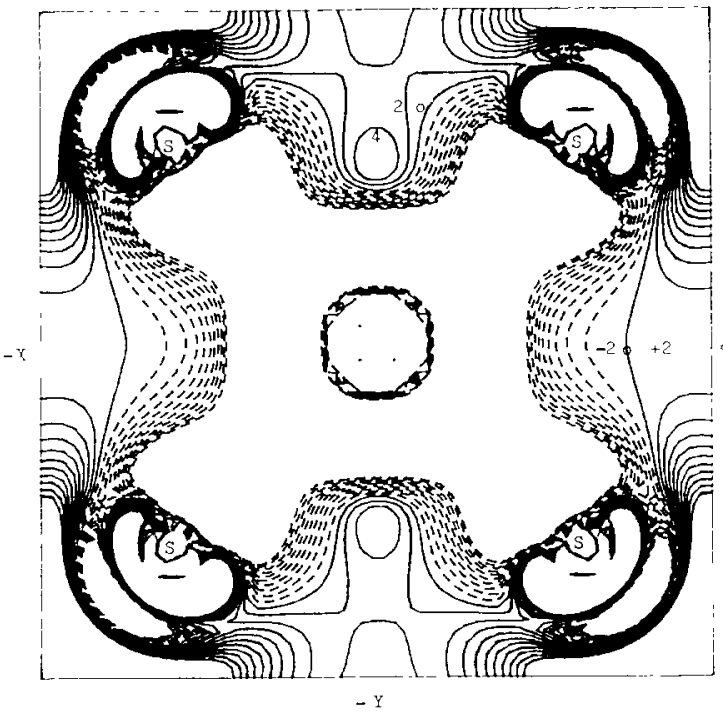

Fig. 4 Difference in charge density between $\mathrm{TlS}_{7}$ and $\mathrm{PbS}_{7}$. (Dashed lines represent negatıve contours and full lines represent positive contours.)

that one of the S atoms, the very one that lies on $z$ the axis, is located at a distance of $0.322 \mathrm{~nm}$ from the central atom, while the other two are located at a distance of $0.374 \mathrm{~nm}$ from the central atom. The crosshatched surfaces given in figs. 5 and 6 are fields of the same electron density and their different extension partly results from the presence of $4 \mathrm{~S}$ atoms in the $x-y$ plane (although they are out of frame in the given figures) and partly from the various natures of the clusters.

The coordination number 7 in case of the $\mathrm{Tl}$ atom represents a common coordination of this heavy metal.

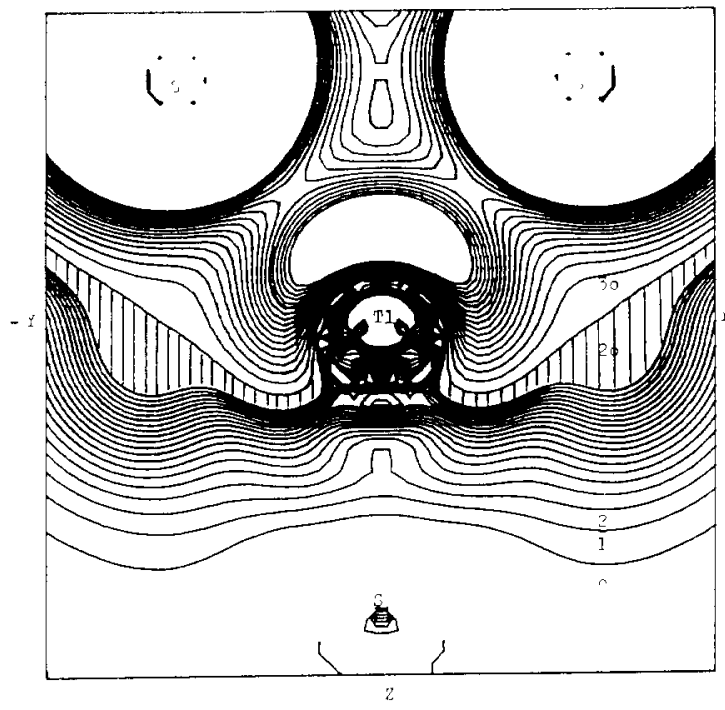

Fig. $5 \mathrm{TlS}_{7}^{-1.3}$ cluster; electron density plot in the $y-z$ plane. 


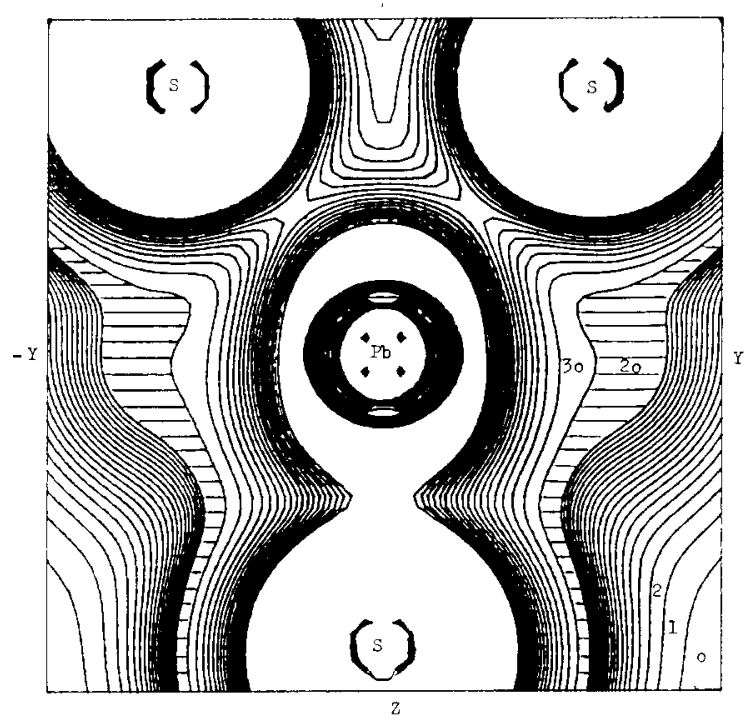

F1g. 6. $\mathrm{PbS}_{7}^{-13}$ cluster; electron density plot in the $y-z$ plane. (The cross-hatched surface is of the same density as the one in fig. 5.)

The voluminosity of the electron shell and the presence of one unpaired electron in the $6 \mathrm{p}$ orbital of ${ }_{81} \mathrm{Tl}$ give preference to asymmetric coordination media. Contrary to thallium, ${ }_{82} \mathrm{~Pb}$ is characterized by one electron pair in the $6 \mathrm{p}$ orbital which certainly influences $\mathrm{Pb}$ to form compounds where it is located in a coordination geometry which is almost always based on the galenite crystal lattice [8].

Having in mind all the above mentioned, we expected great differences in electron density distribution between $\mathrm{Tl}$ and $\mathrm{S}$ and between $\mathrm{Pb}$ and $\mathrm{S}$. It is quite obvious that where the first model is concerned $\left(\mathrm{TlS}_{7}^{-13}\right)$ the electron density is mainly concentrated between $\mathrm{Tl}$ and $4 \mathrm{~S}$ atoms in the $x-y$ plane and $\mathrm{Tl}$ and $2 \mathrm{~S}$ atoms in the $y-z$ plane, while it is somewhat lower in the vicinity of the $\mathrm{S}$ atom located on the $z$ axis. Where the second model is concerned $\left(\mathrm{PbS}_{7}^{-13}\right)$ a tendency of the charge to shift towards a part of the cluster that has all the characteristics of a galenite structure is noticed. The two residual $\mathrm{S}$ atoms in the $y-z$ plane are in a field of considerably lower electron density. These changes in electron densities are shown in fig. 7 representing the difference in electron densities between $\mathrm{TIS}_{7}^{-13}$ and $\mathrm{PbS}_{7}^{-13}$ clusters in the $y-z$ plane. It is obvious from fig. 7 that the electron density is considerably higher in the vicinity of $\mathrm{Pb}$ atoms and is concentrated between $\mathrm{Pb}, \mathrm{S}$ atoms along the $z$ axis and $4 \mathrm{~S}$ in the $x-y$ plane (fig. 4 ). The change in $\mathrm{Tl}$ cluster is shifted towards $\mathrm{S}$ atoms in the $y-z$ plane (fig. 7) which means that the strength of the chemical bond between $\mathrm{Pb}$ and the mentioned $5 \mathrm{~S}$ atoms is considerably stronger when compared to the strength of the chemical bond with the remaining two $\mathrm{S}$ atoms in the $y-z$ plane in the $\mathrm{PbS}_{7}^{-13}$ cluster. This

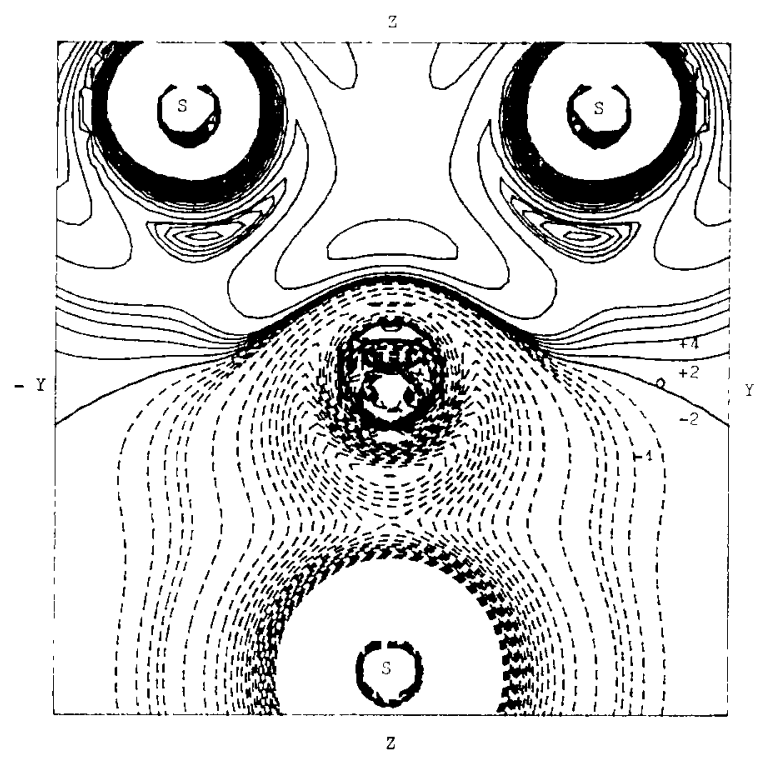

Fig. 7. The difference in electron density between $\operatorname{TIS}_{7}^{-13}$ and $\mathrm{PbS}_{7}^{-13}$ clusters (the dashed line represents negative values).

argument is not valid for the $\mathrm{TlS}_{7}$ cluster. Therefore, we can expect the presence of $\mathrm{Pb}$ in a lorandite lattice to weaken the bond between two neighbouring layers particularly at sites where $\mathrm{Pb}$ is built in instead of $\mathrm{Tl}$. The discussion of Balić-Žunić [9] speaks in favour of the results obtained.

The eigenvector values are represented in table 1 , from which it is evident that in the case of $\mathrm{TIS}_{7}^{-13}$ the ergenvalue for the highest electronic state is approximately $1.7 \mathrm{eV}$ below the Fermı energy level which is at $-1.48 \mathrm{eV}$, while in the case of $\mathrm{PbS}_{7}^{-13}$ the outer filled electron level lies at the very Fermi energy level $(-1.43$ $\mathrm{eV}$ ). Analysing other eigenvalues we found them to be similarly arranged within the energety scale in both
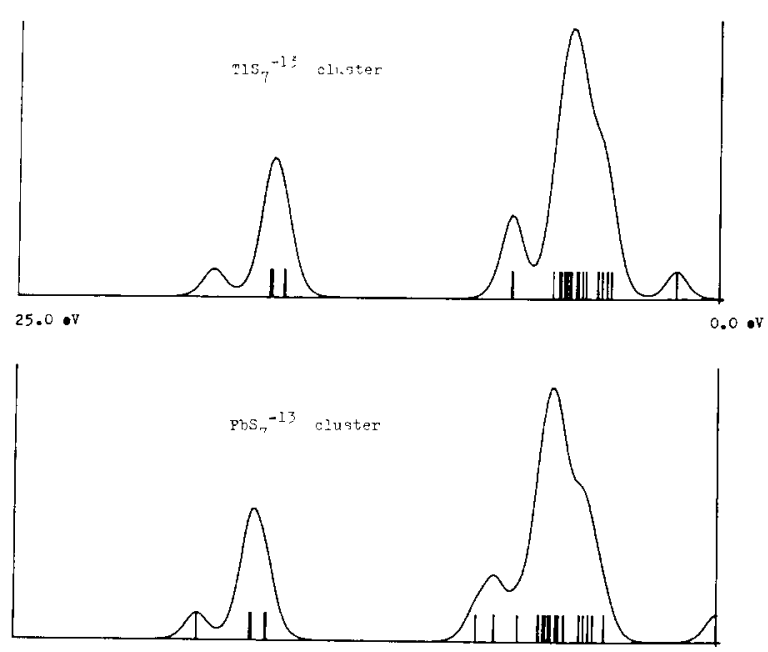

Fig. 8. Plot of the density of states plot. 
Table 1

Results of DVM calculations, Eigenvalues and occupation of levels

\begin{tabular}{|c|c|c|c|c|c|}
\hline \multicolumn{3}{|c|}{$\mathrm{TlS}_{7}^{-13}$ cluster (system of 58 electrons) } & \multicolumn{3}{|c|}{$\mathrm{PbS}_{7}^{-13}$ cluster (system of 59 electrons) } \\
\hline State & Eigenvalue $[\mathrm{eV}]$ & Occupation & State & Eigenvalue $[\mathrm{eV}]$ & Occupation \\
\hline $1 \mathrm{~A} 1$ & -17.5493 & 2 & $1 \mathrm{Al}$ & -17.5407 & 2 \\
\hline $2 \mathrm{~B} 2$ & -15.8196 & 2 & $2 \mathrm{~B} 2$ & -15.9229 & 2 \\
\hline $3 \mathrm{~B} 1$ & -15.8175 & 2 & $3 \mathrm{~B} 1$ & -15.9176 & 2 \\
\hline $4 \mathrm{~A} 1$ & -15.8028 & 2 & $4 \mathrm{Al}$ & -15.9162 & 2 \\
\hline $5 \mathrm{~A} 2$ & -15.7415 & 2 & $5 \mathrm{~A} 2$ & -15.8427 & 2 \\
\hline $6 \mathrm{Al}$ & -15.3826 & 2 & $6 \mathrm{Al}$ & -15.4409 & 2 \\
\hline $7 \mathrm{~B} 2$ & -15.3518 & 2 & $7 \mathrm{~B} 2$ & -15.4072 & 2 \\
\hline $8 \mathrm{~B} 1$ & -8.3729 & 2 & $8 \mathrm{Al}$ & -8.9465 & 2 \\
\hline $9 \mathrm{~B} 2$ & -8.3701 & 2 & $9 \mathrm{~B} 1$ & -8.3946 & 2 \\
\hline $10 \mathrm{~A} 1$ & -8.3363 & 2 & $10 \mathrm{~B} 2$ & -8.3915 & 2 \\
\hline $11 \mathrm{~A} 1$ & -7.0660 & 2 & $11 \mathrm{~A} 1$ & -7.6726 & 2 \\
\hline $12 \mathrm{~A} 1$ & -6.8743 & 2 & $12 \mathrm{~A} 1$ & -7.0440 & 2 \\
\hline $13 \mathrm{~B} 1$ & -6.8047 & 2 & $13 \mathrm{~B} 1$ & -7.0102 & 2 \\
\hline $14 \mathrm{~B} 1$ & -6.7068 & 2 & $14 \mathrm{~B} 2$ & -6.8828 & 2 \\
\hline $15 \mathrm{~B} 2$ & -6.6838 & 2 & $15 \mathrm{~B} 1$ & -6.8035 & 2 \\
\hline $16 \mathrm{~A} 2$ & -6.6168 & 2 & $16 \mathrm{~A} 2$ & -6.7138 & 2 \\
\hline $17 \mathrm{~A} 1$ & -6.5281 & 2 & $17 \mathrm{~A} 1$ & -6.6740 & 2 \\
\hline $18 \mathrm{~B} 2$ & -6.4940 & 2 & $18 \mathrm{~B} 2$ & -6.6379 & 2 \\
\hline $19 \mathrm{~B} 2$ & -6.3361 & 2 & $19 \mathrm{~B} 2$ & -6.4903 & 2 \\
\hline $20 \mathrm{~A} 2$ & -6.2698 & 2 & $20 \mathrm{~B} 1$ & -6.4355 & 2 \\
\hline $21 \mathrm{~B} 1$ & -6.2635 & 2 & $21 \mathrm{~A} 2$ & -6.3903 & 2 \\
\hline $22 \mathrm{Al}$ & -6.1351 & 2 & $22 \mathrm{~A} 1$ & -6.2342 & 2 \\
\hline $23 \mathrm{~A} 2$ & -6.0328 & 2 & $23 \mathrm{~A} 2$ & -62105 & 2 \\
\hline $24 \mathrm{~B} 2$ & -5.6763 & 2 & $24 \mathrm{~B} 2$ & -5.7533 & 2 \\
\hline $25 \mathrm{~B} 1$ & -5.6522 & 2 & $25 \mathrm{~B} 1$ & -5.7301 & 2 \\
\hline $26 \mathrm{~A} 2$ & -5.5271 & 2 & $26 \mathrm{~A} 2$ & -5.6080 & 2 \\
\hline $27 \mathrm{~A} 1$ & -5.3683 & 2 & $27 \mathrm{~A} 1$ & -5.4719 & 2 \\
\hline $28 \mathrm{~B} 2$ & -5.2400 & 2 & $28 \mathrm{~B} 2$ & -5.3292 & 2 \\
\hline $29 \mathrm{Al}$ & -3.1934 & 2 & $29 \mathrm{~A} 1$ & -4.9735 & 2 \\
\hline $30 \mathrm{Al}$ & -0.4818 & 0 & $30 \mathrm{Al}$ & -1.4336 & 1 \\
\hline \multirow[t]{2}{*}{$31 \mathrm{~B} 1$} & -0.4608 & 0 & $31 \mathrm{~B} 1$ & -1.2741 & 0 \\
\hline & & & $32 \mathrm{~B} 2$ & -0.8316 & 0 \\
\hline \multicolumn{3}{|c|}{$E_{\mathrm{F}}=-148 \mathrm{eV}$} & \multicolumn{3}{|c|}{$E_{\mathrm{F}}=-1.43 \mathrm{eV}$} \\
\hline
\end{tabular}

clusters, which was also confirmed by diagrams of the energety density of states (fig. 8). The main differences are observed in the region of the Fermi energy level. Apart from this it should be emphasized that the mentioned diagrams present only molecular orbitals occupied by valence electrons, but not the inner electrons of a metal and sulphur. Another conclusion can be made on the basis of the results presented in table 1 and fig. 8 , i.e. that the electron conductivity of lorandite enriched by lead is considerably higher than that of pure lorandite. But this conclusion requires experimental confirmation.

\section{Conclusion}

On the basis of the performed analysis of a simplified lorandite model, when only a metal and its nearest neighbours, $7 \mathrm{~S}$ atoms, are taken into consideration, the assumption can be made that the conversion of $\mathrm{Tl}$ into $\mathrm{Pb}$ during neutrino capture causes a local distortion of the lattice geometry and consequently destabilizes the lattice.

The mentioned destabilization is expressed in the weakening of the bond between the layers with cubic symmetry particularly at sites where the $\mathrm{Pb}$ atoms make a bond with $\mathrm{S}$ atoms from the neighbouring layer.

The analysis of electron density enables us to conclude that $\mathrm{Pb}$ in a lattice formed of $\mathrm{TlS}_{7}^{-13}$ clusters favours a redistribution of electron density that characterizes octahedral symmetry. Apart from a minimum difference of atomic number between $\mathrm{Tl}$ and $\mathrm{Pb}$, the electron density is considerably higher near $\mathrm{Pb}$, particularly in the $x-y$ plane (fig. 4) thus supporting the fact that the chemical bond is more localized between $\mathrm{Pb}$ and $S$ than between $T 1$ and $S$ withn the same layer. On 
the contrary, the electron density is distributed more difusely in the case of the $\mathrm{Tl} \mathrm{S}_{7}$ cluster. This means that the ion character of the bond between $\mathrm{Pb}$ and $\mathrm{S}$ is slightly more marked. We can also suppose that a diffusion process of $\mathrm{Pb}$ could also be possible under the necessary physico-chemical conditions.

\section{Acknowledgement}

The author wishes to thank Dr. Bengt Lindgren from the University of Uppsala for his valuable help and discussions during the preparation of this paper.

\section{References}

[1] M.K. Pavićević, GSI-86-9 report (1986) p. 1.

[2] J.C. Slater and K.H. Johnson, Phys. Rev. B5 (1972) 844.

[3] H.L. Skriver, The LMTO method (Springer, Berlın, 1984).

[4] E.J. Baerends, D.E. Ellis and P. Ros. Chem. Phys. 2 (1973) 41.

[5] B. Delley and D.E. Ellis, J. Chem. Phys. 76 (1982) 1949.

[6] B. Lindgren and D.E. Ellis, Phys. Rev. B26 (1982) 636.

[7] M.E. Fleet, Z. Kristallogr. 138 (1973) 147.

[8] E. Makoviscky, NATO ASI Senes E: Applied Sciences no. 83 (1984) p. 159.

[9] T. Balıć-Žunić and S. Ščavnićar, these Proceedıngs (Int. Conf. on Solar Neutrino Detection with ${ }^{205} \mathrm{Tl}$, and Related Topics, Dubrovnik 1986) Nucl. Instr, and Meth. A271 (1988) 301. 